\title{
Kronik ürtikerli hastalarda troid otoimmünitesi ve artmış nötrofil lenfosit oranı
}

\section{Thyroid autoimmunity and increased neutrophil lymphocyte ratio in patients with chronic urticaria}

\author{
Tuğba Songül TAT*
}

Dr. Ersin Arslan Eğitim ve Araştırma Hastanesi, İmmünoloji ve Allerji Hastalıkları ABD, Gaziantep/TÜRKIYE

\section{Öz}

Amaç: Kronik ürtikerin (KÜ) etyopatogenezi henüz net değildir. Ancak otoimmünitenin ve inflamasyonun rol oynadığı yapılan çalışmalarda gösterilmiştir. Bu çalışmamızda KÜ'li hastalarda tiroid otoimmünitesinin saptanması, hastalık şiddetiyle ilişkisinin araştırılması ve inflamatuar belirteçler olan nötrofil lenfosit oranı (NLO), eosinofil lenfosit oranı (ELO) ve monosit lenfosit oranlarının (MLO) kontrol grup ile karşılaştırılması amaçlanmıştır.

Gereç ve Yöntemler: Erişkin allerji-immünoloji polikliniğinde KÜ nedeniyle takip edilen hastaların kayıtları geriye dönük olarak incelendi. Çalışmaya 100 KÜ'li hasta ve kontrol grubu olarak 100 sağlıklı birey alındı. KÜ'li hastaların demografik verileri, yedi günlük ürtikeryal aktivite skorları (UAS 7), kullandığı ilaçlar, laboratuar verilerinden anti-tiroglobülin (anti-Tg) ve anti-tiroid peroksidaz (anti-Tpo), antinükleer antikor (ANA) sonuçları ve kan sayımı parametreleri kayıt edildi. Kontrol grubu olarak yaş ve cinsiyet uyumlu sağlıklı bireylerin kan sayımı parametreleri kayıt edildi.

Bulgular: KÜ hastalarda anti-Tpo \% 19 hastada pozitif iken, anti-Tg \% 8, ANA \% 17 hastada pozitif idi. KÜ hastalar UAS 7'ye göre hafif, orta ve şiddetli olarak, gruplara ayrılarak değerlendirildiğinde, gruplar arası anti-Tpo, anti-Tg ve ANA sonuçları açısından fark saptanmadı ( $p>0,05)$. KÜ hastalar ve kontrol grupları arasında NLO, MLO ve ELO kıyaslandığında, NLO ve MLO istatistiksel olarak anlamlı yüksek tespit edilirken ( $p=0,028, p=0,001$, sırasıyla) ELO açısından istatistiksel olarak anlamlı fark yoktu ( $p=0,094)$. KÜ'li hastalarda NLO, MLO ve ELO değerleri anti-Tpo, anti-Tg ve ANA pozitif ve negatif olan gruplar arasında kıyaslandığında anlamlı fark saptanmadı ( $p>0,05)$.

Sonuç: KÜ'de otoimmünitenin ve inflamasyonun önemi yapılan çalışmalarda gösterilmişti. Ek olarak bu çalışmada hastalık aktivitesi ile tiroid otoimmünitesi arasında ilişki saptanmazken inflamatuar bir belirteç olan NLO'ya ek olarak MLO da yüksek olarak tespit edildi.

Anahtar kelimeler: Kronik ürtiker; tiroid otoimmünitesi; nötrofil lenfosit oranı; monosit lenfosit oranı, eosinofil lenfosit oranı; ürtikerde otoimmünite

Sorumlu yazar: Tuğba Songül Tat, Dr. Ersin Arslan Eğitim ve Araştırma Hastanesi, İmmünoloji ve Allerji Hastalıkları ABD, Gaziantep/TÜRKiYE E-posta: tugbasongultat@yahoo.com

ORCID: 0000-0001-6752-320

Gönderim : 01.02.2019 Kabul: 10.02.2019

Doi: $10.18663 /$ tjcl.521024 


\section{ABSTRACT}

Aim: The etiopathogenesis of chronic urticaria (CU) is not clear yet. However, it has been shown that autoimmunity and inflammation play important roles in most of the studies. In this study, we aimed to determine the prevalence of thyroid autoimmunity in patients with $\mathrm{CU}$ and to investigate the relationship between the severity of the disease and thyroid autoimmunity. and also we aimed to compare the neutrophil lymphocyte ratio (NLR), eosinophil lymphocyte ratio (ELR) and monocyte lymphocyte ratio (MLR) which are inflammatory markers between the CU group and the control group.

Material and Methods: Medical records of CU patients who were followed in adult allergy-immunology policlinic were retrospectively analyzed. A total of 100 patients with $\mathrm{CU}$ and 100 healthy subjects were included in the study. Patients' demographic datas, seven-day urticarial activity scores (UAS 7), drugs that were used, anti-thyroglobulin (anti-Tg) and anti-thyroid peroxidase (anti-Tpo), anti-nuclear antibody (ANA) and blood count parameters as laboratory data were recorded. As control group blood count parameters of healthy individuals that age and gender-matched were recorded.

Results: Anti-Tpo was positive in 19\%, anti-Tpo was positive in $8 \%$ and ANA was positive in 17\% of the patients with CU. When we divided patients with CU according to UAS 7 into three groups as mild, moderate and severe, there were no significant difference between the groups as anti-Tpo, anti-Tg and ANA results ( $p>0.05)$. When we compare NLR, MLR and ELR parameters between the patients and healthy group,we found that NLR and MLR parameters were statistically significant higher in patients groups $(P=0.028, p=0.001$, respectively) but there was no difference between the groups as ELR parameter $(p=0,094)$. When we classified patients with CU as anti-Tpo, anti-Tg and ANA positive and negative, there were no significant differences between the groups as NLR, MLR and ELR results ( $p>0.05)$.

Conclusion: The importance of autoimmunity and inflammation in CU has been shown in studies. In addition, in this study the relationship between the disease activity of urticaria and the thyroid autoimmunity was not determined but the NLR and MLR parameters were found higher in CU as inflammatory markers.

Keywords: Chronic urticaria; thyroid autoimmunity; neutrophil lymphocyte ratio; monocyte-lymphocyte ratio; eosinophil lymphocyte ratio; autoimmunity in urticaria

\section{Giriş}

Ürtiker tüm toplumlarda sık görülen ve aniden ortaya çıkıp 1-24 sa içinde kendiliğinden kaybolan kaşıntılı ve farklı boyutlarda ödemli plaklar ile karakterize bir deri hastalığıdır. Cilt lezyonlarının 6 haftadan uzun sürdüğünde kronik ürtiker (KÜ) olarak tanımlanmaktadır [1]. Genel popülasyonda prevelansının \%0,5 den \%5' e kadar değiştiği bildirilmekte olup, önemli bir sağlık sorunudur [2].

KÜ etiyolojisinde sorumlu tutulan birçok neden vardır. Başlıca spontan ve uyarılabilir ürtiker olarak iki ana gruba ayrılmaktadır [1].Uyarılabilir ürtikerde neden çoğunlukla bellidir. Spontan ürtiker etiyolojisinde ise ilaçlar, gıdalar, gıda katkı maddeleri, enfeksiyonlar ve parazitik enfestasyonlar, allerjenler, otoimmünite, maligniteler ve diğer dermatolojik hastalıklar, psikolojik faktörler yer alsa da çoğu hastada etyoloji saptanamamaktadır [3,4 ]. Nötrofil lenfosit oranı (NLO), platelet lenfosit oranı gibi inflamatuar göstergelerin hastalık aktivitesi ve prognozla ilişkisi bir çok dermatolojik hastalıklarda gösterilmiştir [5,6].

Bu çalışmada KÜ'li hastalarda tiroid otoimmünitesi sıklığının saptanması, tiroid otoimmünitesinin hastalık şiddetiyle ilişkisinin araştırılması ve inflamatuar belirteçler olan NLO, eosinofil lenfosit (ELO) ve monosit lenfosit oranlarının (MLO) kontrol grup ile karşılaştırılması amaçlanmıştır.

\section{Gereç ve Yöntemler}

\section{Hasta seçimi}

Dr. Ersin Arslan Eğitim ve Araştırma Hastanesi erişkin Allerjiİmmünoloji polikliniğinde, 2018 yılında KÜ nedeniyle takip edilen 100 erişkin hasta çalışmaya dahil edildi. Bu hastaların tanısı EAACl/ GA2LEN/EDF/WAO ürtiker klavuzuna göre, kaşıntılı ve ödemli papül/plaklarla veya anjioödem ile ya da her ikisinin birden gelişimiyle kendini gösteren lezyonların hastalarda altı haftadan daha uzun süreli görülmesi ile konuldu [1]. Fiziksel ürtikeri olanlar çalışma dışı bırakıldı. Hastalara ait demografik, klinik ve laboratuar verileri otomasyon sistemine kayıtlı hasta dosyalarından geriye dönük olarak taranarak elde edildi. Aktif enfeksiyonu olanlar ve tiroid uyarıcı hormonu normal sınırlarda olmayanlar çalışma dışı bırakıldı. Hastaların dosyalarından cinsiyet, yaş, hastalık süresi, kullandığı ilaçlar, ek hastalıkları olup olmadığı, yedi günlük ürtikeryal aktivite skorları (UAS 7) kayıt edildi. Laboratuar verisi 
olarak serum anti-tiroglobülin (anti-Tg) ve anti-tiroid peroksidaz (anti-Tpo), antinükleer antikor (ANA) sonuçları ve kan sayımı parametrelerinden nötrofil, eosinofil, lenfosit, monosit değerleri kayıt edildi. Hastalık şiddetinin değerlendirilmesinde Türkiye Ürtiker Tanı ve Tedavi Klavuzunda belirtildiği şekilde hasta tarafından günlük olarak kabarıklık sayısını (0-3 puan) ve kaşıntı şiddetinin (0-3 puan) belirtilmesine dayanan bir skorlama olan UAS'ın yedi gün süresince hesaplanması sonucu bulunan UAS 7 kullanıldı. UAS 7 skoruna göre (minimum 0-maksimum 42) $\leq 6$ iyi kontrollü, 7-15 arası olması hafif, 16-27 arası olması orta ve 28-42 olması ise şiddetli ürtiker olarak değerlendirildi. Kontrol grubu olarak hasta grubu ile yaş ve cinsiyet olarak uyumlu 100 sağlıklı kişinin kan sayımı sonuçları kayıt edildi. Çalışma için yerel etik kurul onayı alındı. Hasta onam formları imzalatıldı.

\section{İstatistiksel Analiz}

Araştırma verilerinin istatistiksel analizlerinde tanımlayıcı istatistikler kısmında kategorik değişkenler sayı, yüzde verilerek, sürekli değişkenler ise ortalama \pm standart sapma ve ortanca (minimum-maksimum) ile sunulmuştur. Sürekli değişkenlerin normal dağılıma uygunluğu görsel (histogram ve olasılık grafikleri) ve analitik yöntemler (KolmogorovSmirnov/Shapiro-Wilk testleri) kullanılarak değerlendirilmiştir. Yapılan normallik analizleri sonucu sürekli değişkenlere ait verilerin normal dağılmadığı saptanmıştır. Normal dağılıma uymayan bu verilerin, iki grup arasındaki karşılaştırma analizleri için Mann-Whitney $U$ testi, 3 grup arasındaki karşılaştırma analizleri için Kruskal Wallis testi kullanılmıştır. Bazı sürekli değişkenler arasındaki ilişki Sperman korelasyon testi ile değerlendirilmiştir. Bağımsız gruplar arasında kategorik değişkenler için yapılan karşılaştırma analizinde Pearson ki-kare testi kullanılmıştır. Bu çalışmada istatistik anlamlılık seviyesi $\mathrm{p}<0,05$ olarak kabul edilmiştir.

\section{Bulgular}

Çalışmaya alınan 100 KÜ'li hastanın \%69 u kadın olup yaş ortalaması 38,2+/-13,7 idi. İlk başvuru anında hastaların \% 45'inin hastalık şiddeti hafif, \% 41 hastanın orta, \% 14 hastanınki şiddetli idi. KÜ hastalarda anti-Tpo \% 19 hastada pozitif iken, anti-Tg \% 8, ANA \%17 hastada pozitif idi. Hastalar semptomlarına göre hafif, orta ve şiddetli olarak 3 gruba ayrılarak anti-Tpo, anti-Tg ve ANA pozitifliği açısından değerlendirildi. İstatistiksel olarak anlamlı fark saptanmadı. (Tablo 1). Spearman korelasyon testi ile de değerlendirme yapıldı ancak hastalık şiddeti ile anti-Tpo ve anti-Tg arasında istatistiksel olarak anlamlı bir ilişki saptanmadı $(r=0,195$; $p=0,052$ ve $r=0,178 ; p=0,076)$.

\begin{tabular}{|c|c|c|c|c|}
\hline Parametreler & $\begin{array}{l}\text { Hafif ürtiker } \\
\qquad n=45 \\
(\% 45,0)\end{array}$ & $\begin{array}{l}\text { Orta ürtiker } \\
\qquad \begin{array}{c}n=41 \\
(\% 41,0)\end{array}\end{array}$ & $\begin{array}{c}\text { Şiddetli } \\
\text { ürtiker } \\
n=14 \\
(\% 14,0)\end{array}$ & $\begin{array}{c}P \\
\text { değeri }\end{array}$ \\
\hline $\begin{array}{l}\text { Anti-Tpo, n (\%)* } \\
\text { Negatif } \\
\text { Pozitif }\end{array}$ & $\begin{array}{c}38(84,4) \\
7(15,6)\end{array}$ & $\begin{array}{c}33(80,5) \\
8(19,5)\end{array}$ & $\begin{array}{c}10(71,4) \\
4(28,6)\end{array}$ & $0,552^{1}$ \\
\hline $\begin{array}{l}\text { Anti-Tg, n (\%) } \\
\text { Negatif } \\
\text { Pozitif }\end{array}$ & $\begin{array}{c}41(91,1) \\
4(8,9)\end{array}$ & $\begin{array}{c}37(90,2) \\
4(9,8)\end{array}$ & $\begin{array}{c}14(100) \\
0\end{array}$ & AUD \\
\hline $\begin{array}{c}\text { ANA, n (\%) } \\
\text { Negatif } \\
\text { Pozitif }\end{array}$ & $\begin{array}{c}36(80,0) \\
9(20,0)\end{array}$ & $\begin{array}{c}35(85,4) \\
6(14,6)\end{array}$ & $\begin{array}{c}12(85,7) \\
2(14,3)\end{array}$ & $0,770^{1}$ \\
\hline
\end{tabular}

KÜ'li hastalarla kontrol grubu arasında ELO, MLO, NLO değerleri karşılaştırıldı. İki grup arasında NLO ve MLO değerleri arasında anlamlı fark saptanırken ( $p=0,028, p=0,001$, sırasıyla), ELO açısından istatistiksel olarak anlamlı fark yoktu $(p=0,094)$ (Tablo 2). Hastalık şiddeti ile ELO, MLO ve NLO değerleri arasında da istatistiksel anlamlı ilişki saptanmamıştır (Spearman korelasyon testi $r=0,069 ; p=0,497, r=0,099 ; p=0,327$ ve $r=0,122 ; p=0,225$, sirasıyla).

\begin{tabular}{|c|c|c|c|}
\hline Parametreler & $\begin{array}{l}\text { Kronik Ürtiker } \\
n=100(\% 50,0)\end{array}$ & $\begin{array}{c}\text { Kontrol } \\
n=100(\% 50,0)\end{array}$ & $\begin{array}{c}P \\
\text { değeri }\end{array}$ \\
\hline $\begin{array}{l}\text { Cinsiyet, } \mathrm{n}(\%) \\
\text { Kadın } \\
\text { Erkek }\end{array}$ & $\begin{array}{l}69(69,0) \\
31(31,0)\end{array}$ & $\begin{array}{l}71(71,0) \\
29(29,0)\end{array}$ & 0,7581 \\
\hline $\begin{array}{l}\text { Yaş (yıl) } \\
\text { Ortalama } \pm \text { ss } \\
\text { Ortanca(min-mak) }\end{array}$ & $\begin{array}{c}38,24 \pm 13,71 \\
35,5(18,0-74,0)\end{array}$ & $\begin{array}{c}39,44 \pm 12,81 \\
37,5(19,0-76,0)\end{array}$ & 0,3722 \\
\hline $\begin{array}{l}\text { Eosinofil/Lenfosit } \\
\text { Ortalama } \pm \text { ss } \\
\text { Ortanca(min-mak) }\end{array}$ & $\begin{array}{c}0,07 \pm 0,07 \\
0,05(0-0,37)\end{array}$ & $\begin{array}{c}0,06 \pm 0,05 \\
0,06(0-21,0)\end{array}$ & 0,0942 \\
\hline $\begin{array}{l}\text { Monosit/Lenfosit } \\
\text { Ortalama } \pm \text { ss } \\
\text { Ortanca(min-mak) }\end{array}$ & $\begin{array}{c}0,27 \pm 0,13 \\
0,23(0,09-1,14)\end{array}$ & $\begin{array}{c}0,18 \pm 0,07 \\
0,17(0,06-0,51)\end{array}$ & 0,0012 \\
\hline $\begin{array}{l}\text { Nötrofil/Lenfosit } \\
\text { Ortalama } \pm \text { ss } \\
\text { Ortanca(min-mak) }\end{array}$ & $\begin{array}{c}2,29 \pm 1,24 \\
1,96(0,72-9,51)\end{array}$ & $\begin{array}{c}1,88 \pm 0,69 \\
1,75(0,75-3,68)\end{array}$ & 0,0282 \\
\hline 'Pearson Ki-kare testi, & ${ }^{2}$ Mann Whitney U & & \\
\hline
\end{tabular}

KÜ'li grupta ELO, MLO, NLO değerleri hastalık şiddetine, antiTpo, anti-Tg ve ANA sonuçlarına göre değerlendirildi. Ancak gruplar arasında istatistiksel olarak anlamlı fark saptanmadı ( $p>0,05)$ (Tablo 3). 


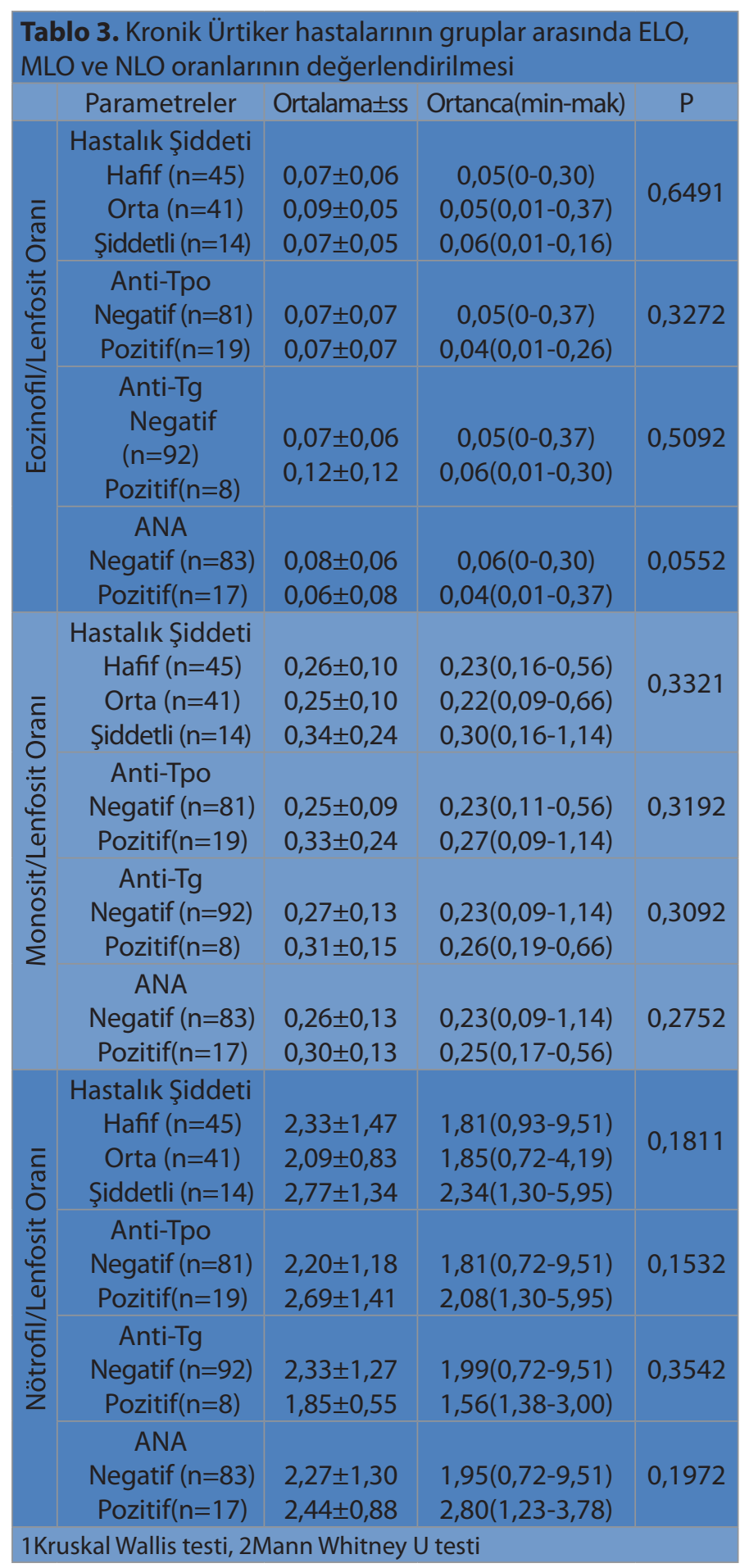

\section{Tartışma}

KÜ etyopatogenezi henüz net olmamakla birlikte, hastalığın değerlendirilmesinde klavuzlara göre UAS ile şiddetinin değerlendirilmesi önerilmekte iken ek olarak etyolojiye yönelik tam kan sayımı, CRP, eritrosit sedimantasyon hızı bakılması, hastanın öyküsüne göre diğer ayrıntılı tetkiklerin yapılması gerektiği belirtilmiştir [3]. Bizim hasta grubumuzda da etyolojiyi saptamaya yönelik yapılan tetkiklerde otoantikorlardan anti-
Tpo \% 19 hastada pozitif iken, anti-Tg \% 8, ANA \%17, toplamda 100 hastanın 37'sinde bu belirteçlerden en az biri pozitif olarak tespit edildi. Ancak hastalık şiddeti ile ilişkisi tespit edilemedi. Yapılan bir çok çalışmada ürtikerin otoimmün ilişkisi ortaya konulmuştur [7] ve bu hastalık gruplarından en sık olarak da tiroid hastalıklarının eşlik ettiği bildirilmiştir.

Literatüre baktığımızda Akarsu ve arkadaşları KÜ'li 146 hastanın \%9,6 sında anti-tiroid peroksidaz, \%4,8'inde anti-tiroglobulini pozitif bulmuşlardır [8]. Angulo ve ark. 343 KÜ'li hasta ve 282 sağlıklı gönüllüleri karşılaştırdıkları çalışmalarında KÜ'li hastalarda anti-Tpo \%20.4, anti-Tg \%15,2 olarak saptamışlar ve kontrol grubu ile kıyasladıklarında anlamlı ölçüde yükseklik tespit etmişler $(p<0.001)$ [9]. Cebeci ve ark. yaptıkları çalışmalarında otoimmün tiroidi KÜ hastalarında \%44,2 oranında bulmuşlardır [10]. Haliloviç ve ark KÜ li hastalarda anti-Tg'i \% 23, anti-TPO \% 30 hastada pozitif tespit etmişken, kontrol grubunda 2 kişide $(\% 2,86)$ pozitif tiroid otoimmünitesi saptamışlar ve iki grubu kıyaslayınca istatistiksel olarak anlamlı ölçüde KÜ'li grupta yükseklik tespit etmişlerdir [11]. Ancak farklı olarak Ülker ve ark. yaptıkları çalışmada 77 KÜ'li hasta ve kontrol grubunda anti-TPO ve anti-TG düzeyleri karşılaştırmışlar ancak her iki grup arasında anlamlı farklılık saptamamışlardır [12].

Bu çalışmada KÜ'li hastalarla kontrol grubu ELO, MLO, NLO değerleri karşılaştırıldığında iki grup arasında NLO ve MLO değerleri arasında anlamlı fark saptanırken ELO açısından istatistiksel olarak anlamlı fark saptanmadı. Ek olarak KÜ'li grupta ELO, MLO, NLO değerleri hastalık şiddetine, anti-Tpo, anti-Tg ve ANA sonuçlarına göre değerlendirildi. Ancak gruplar arasında istatistiksel olarak anlamlı fark saptanmadı. Saraç ve ark. ürtikerde yapmış oldukları çalışmalarında NLO değerini akut ürtiker, kronik ürtiker ve kontrol grupları arasında kıyaslamışlar ve anlamlı fark bulmuşlar $(p<0,001)$ ancak KÜ de hastalık süresi 90 gün altı ve üstü olan hasta gruplarını karşılaştırınca anlamlı fark bulmamışlardır [13]. Karabay ve arkadaşları NLO ve CRP düzeylerini KÜ hastalarında sağlıklı kontrollere göre anlamlı olarak daha yüksek saptamışlar $(p<0,001)$ ancak hastalık şiddeti ile bu değerler arasında bu çalışmada olduğu gibi bir ilişki saptamamışlardır [14].

\section{Sonuç}

KÜ'in etyopatogenezi tam aydınlatılamamış olsa da, otoimmünitenin de rol oynadığı ve inflamasyonun da mevcut olduğu bir hastalık olduğu bilinmektedir. Bu çalışmada da literatür ile uyumlu sonuçlar bulunmuştur. Ancak KÜ de hastalık şiddetini etkileyen faktörler üzerine ve inflamatuar 
bir belirteç olduğu kanıtlanmış olan NLO değerinin KÜ'de yeri üzerine daha fazla sayıda çalışmaya ihtiyaç vardır.

\section{Çıkar çatışması / finansal destek beyanı}

Bu yazıdaki hiçbir yazarın herhangi bir çıkar çatışması yoktur. Yazının herhangi bir finansal desteği yoktur

\section{Kaynaklar}

1. Zuberbier T, Aberer W, Asero $R$ et al. The EAACI/GA2LEN/EDF/ WAO guide $\neg$ line for the definition, classification, diagnosis and management of urtiᄀcaria. Allergy 2018; 73: 1393-414.

2. Bernstein JA, Lang DM, Khan DA et al. The diagnosis and management of acute and chronic urticaria: 2014 update. J Allergy Clin Immunol 2014; 133: 1270-77.

3. Kocatürk Göncü $E$, Aktan Ş, Atakan $N$ et al. Türkiye Ürtiker Tanı ve Tedavi Kılavuzu-2016. Turkderm - Arch Turk Dermatol Venerology 2016; 50: 82-98.

4. Tat TS. Higher Levels of Depression and Anxiety in Patients with Chronic Urticaria. Med Sci Monit 2019; 25: 115-20.

5. Ozturk C, Balta S, Balta I et al. Neutrophil-lymphocyte ratio and carotid-intima media thickness in patients with Behcet disease without cardiovascular involvement. Angiology 2014; 66: 291-96.

6. Ma J, Kuzman J, Ray A et al. Neutrophil-to-lymphocyte Ratio (NLR) as a predictor for recurrence in patients with stage III melanoma. Sci Rep 2018; 8: 4044.

7. Antia C, Baquerizo K, Korman A, Bernstein JA, Alikhan A. Urticaria: A comprehensive review: Epidemiology, diagnosis, andwork-up. J Am Acad Dermatol 2018; 79: 599-614.
8. Akarsu S, IlknurT, Özbagçıvan Ö, Fetil E. Kronik spontan ürtiker ve ürtikeryal vaskülitli olgulardaki eşlik eden durumlar: Retrospektif bir çalışmanın sonuçları. Türkderm 2015; 49: 18-24.

9. Díaz-Angulo S, López-Hoyos $M$, MuñozCacho P, Fernández $M$, López-Escobar M, Rodríguez F, González-López MA. Prevalence of thyroid autoimmunity in spanish patients with chronic idiopathic urticaria: a case-controlstudy involving 343 subjects. J Eur Acad Dermatol Venereol 2016; 30: 692-93.

10. Cebeci F, Tanrikut A, Topcu E et al. Association between chronic urticaria And thyroid autoimmunity. Eur J Dermatol 2006; 16: 402-5.

11. Kasumagic-Halilovic E, Beslic N, Ovcina-Kurtovic N. Thyroid Autoimmunity in Patients with Chronic Urticaria. Med Arch 2017; 71: 29-31.

12. Gül Ü, Çakmak S, Gönül M, Soylu S, Kılıç A. Kronik ürtikerde tiroid fonksiyon testleri ve tiroid otoantikorları istenmeli mi? Asthma Allergy Immunol 2009; 7: 39-43.

13. Saraç G, Mantar I, Sener S, Cenk H, Kapicioglu Y. Assessment of change in neutrophil-lymphocyte ratio, plateletlymphocyteratio in patients with acute and chronic urticaria.J Tugut Ozal Med Cent 2018; 25: 719-22.

14. Karabay EA, Çerman AA, Altunay İK. Serum C-reactive protein, neutrophil-lymphocyte ratio and uric acid levels in chronic spontaneous urticaria. Turkiye Klin J Dermatology 2016; 26: 125-31. 